\title{
Reforma urbana e higiene social en Santiago de Chile. La tecno-utopía liberal de Benjamín Vicuña Mackenna (1872-1875)
}

\author{
César Leyton Robinson (*) y Rafael Huertas (**) \\ (*) Museo de Odontología, Facultad de Odontología, Universidad de Chile, Santiago de Chile. \\ cleyton@odontologia.uchile.cl \\ ${ }^{(*)} \quad$ Instituto de Historia. Centro de Ciencias Humanas y Sociales, CSIC, Madrid. \\ rafael.huertas@cchs.csic.es
}

Dynamis

[0211-9536] 2012; $32(1): 21-44$
Fecha de recepción: 20 de mayo de 2011

Fecha de aceptación: 7 de septiembre de 2011

SUMARIO: 1.- Introducción. 2.-Del viaje iniciático a la voluntad reformadora. 3.-La reforma urbana de Vicuña Mackenna. 3.1.—La ciudad propia: la Montaña Mágica de Santa Lucía. 3.2.—EI aduar africano frente a la ciudad europea. 3.3.-El muro sanitario y la colonización interna.

RESUMEN: Este artículo analiza las características principales de las reformas urbanas propiciadas por Benjamín Vicuña Mackenna en Santiago de Chile entre 1872 y 1875 . Prestaremos especial atención al origen de sus objetivos modernizadores, íntimamente relacionados con el programa de instauración de una cultura (civilización) urbana por parte de la elites latinoamericanas, y analizaremos las estrategias de defensa social que dichas reformas llevaron implícitas. La influencia del positivismo francés y del proyecto de Haussmann en París fueron determinantes en la propuesta de Vicuña Mackenna y en su modelo de ciudad segregada: una ciudad propia - «europea», burguesa, civilizada e higiénica- que debía ser protegida, y un suburbio — «africano», popular, salvaje y antihigiénico- que debía ser regenerado y colonizado.

PALABRAS CLAVE: Higiene, urbanismo, modernización, defensa social, América Latina, Chile, siglo XIX.

KEY WORDS: Hygiene, urbanism, modernization, social defense, Latin America, Chile, 19th century. 


\section{Introducción $\left(^{*}\right)$}

Tras conseguir la independencia en las primeras décadas del siglo XIX, varios países latinoamericanos iniciaron un complejo proceso de formación de sus Estados nacionales ${ }^{1}$. Como es bien sabido, en la construcción de la identidad nacional, el positivismo científico desempeñó un importante papel al ser asumido por una elite intelectual empeñada en el desarrollo social y, en suma, en un ideal de «modernidad»; una modernidad a la que se creía poder llegar mediante la alianza entre tales ideas científicas y los proyectos políticos de un buen número de gobiernos latinoamericanos de la segunda mitad del siglo XIX y las primeras décadas del $\mathrm{XX}^{2}$. La modernización de Argentina, planteada desde Sarmiento en el enfrentamiento entre civilización y barbarie $^{3}$, o de México durante el porfiriato ${ }^{4}$, tienen ese denominador común: la ciencia como gran abanderada del progreso y al servicio de un proyecto político de elite. Un proyecto que, aunque con características locales más o menos específicas, tendrá sus referentes en modelos nacionales occidentales europeos, excluyendo la vieja metrópoli. Como ya hace tiempo explicaba el prestigioso historiador argentino José Luis Romero:

«España fue la tradición y Europa el cambio (...) España fue el pasado y Europa fue el presente y el futuro. La imagen de una Europa sin España arraigó fuertemente en los grupos predominantes. Con ello el juicio sobre el

$\left({ }^{*}\right)$ Trabajo realizado en el marco del proyecto de investigación HAR2009-13389-C03-02, Ministerio de Ciencia e Innovación, España.

1. Las similitudes y diferencias de tales experiencias han sido objeto de importantes investigaciones que ofrecen claves para comprender la situación actual en la zona. Una breve pero interesante reflexión al respecto puede encontrarse en Oszlak, Oscar. El estado democrático en América Latina. Hacia el desarrollo de líneas de investigación. Nueva Sociedad. 2007; 210: $1-14$.

2. Weinberg, Gregorio. La ciencia y la idea de progreso en América Latina (1860-1930). Buenos Aires: Fondo de Cultura Económica; 1998.

3. Sarmiento, Domingo F. Civilización y barbarie. Vida de Juan Facundo Quiroga. Santiago: Imprenta del Progreso; 1845. Véase Botana, Natalio. La tradición republicana. Alberdi, Sarmiento y las ideas de su tiempo. Buenos Aires: Editorial Sudamericana; 1997.

4. Krauze, Enrique; Zerón-Medina, Fausto. Porfirio. El Poder 1884-1900. México: Editorial Clío; 1993. 
europeo adquirió un tono generalizadamente positivo, en tanto que el juicio sobre el español adquirió un tono negativo» ${ }^{5}$.

Así, con la vista puesta en Europa, las elites latinoamericanas apostaron por una modernidad «post-hispana» que, dejando atrás la barbarie representada por la colonia, pretendió tanto la explotación económica y militar de nuevos territorios, como la renovación y extensión de medios de comunicación, creación de instituciones, reformas urbanas y un largo etcétera de iniciativas que, financiadas por empresas privadas extranjeras (europeas o norteamericanas) o por los propios estados-nación, acometieron la tarea ingente de dotar a éstos de la modernidad burguesa y liberal representada por los países europeos más desarrollados. En este contexto, el positivismo francés aparece como una de las corrientes de pensamiento más influyentes en la constitución y desarrollo del mencionado proyecto político. La recepción y reformulación de determinados modelos europeos de intervención social por las clases dominantes de países «periféricos» cumpliría dos funciones básicas: por un lado, levantar toda una superestructura que legitimase su relación de clase poderosa local con el núcleo dominante internacional; y, por otro, ya en el orden interno, fortalecer su propia posición de poder al operar como instrumento de dominación y medio de distinción en relación con las clases o grupos subordinados. En este sentido, como bien ha apuntado Rosa del Olmo en su ya clásico ensayo sobre la criminología en América Latina, las iniciativas políticas y las reformas sociales aparecieron

«[una vez que] sus clases dominantes e "ilustradas" hubieran definido los dictados de la ideología liberal y la filosofía positivista, consideradas como la mejor vía para lograr el "orden y el progreso", pero sobre todo el "orden", el cual consideraban tan necesario, no solo por los largos periodos de anarquía, caudillismo y guerras civiles que habían caracterizado a la historia del siglo XIX latinoamericano, sino también para el proceso de implantación del capitalismo como modo de producción dominante en el área» ${ }^{6}$.

En este contexto, la ciudad aparece como una de las expresiones más acabadas de la modernidad occidental; es más, en el caso latinoamericano,

\footnotetext{
5. Romero, José Luis. Latinoamérica: Situaciones e ideología. Buenos Aires: Ed. del Candil; 1967, p. 33.

6. Olmo, Rosa del. América Latina y su criminología. México: Siglo XXI; 1981, p. 127.
} 
sirve para inventar la modernidad, para extenderla y reproducirla ${ }^{7}$, independientemente de que la urbe en cuestión sea una realidad física o una idea más o menos utópica ${ }^{8}$. La ciudad - lo urbano- surge, en definitiva, como un artefacto ideológico de modernidad ${ }^{9}$. Así es utilizada por Sarmiento a mediados del siglo XIX, como referente simbólico de la civilización ${ }^{10}$-frente a la doble barbarie de la naturaleza americana y el pasado español- incluso antes de que Buenos Aires se convirtiera en un reflejo de París, esa capital europea, ostentosa y refinada, luminosa y moderna, que se convirtió en el modelo ideal de ciudad que las elites latinoamericanas pretendían imitar: «París soberana de ciudades (...) tu hermana muy joven aún, hasta hoy recatada (...) verá que perteneces a la misma estirpe», dirá un texto anónimo en la época del centenario de la capital argentina ${ }^{11}$.

Otras ciudades de América Latina buscarán esa misma identificación con la ciudad burguesa europea, limpia, ordenada y segregada, acorde no con la idea colonialista de las castas, sino con las más modernas nociones de la ciencia y la técnica. Dejando atrás el damero colonial, se va conformando una ciudad orgánica, sometida a flujos de todo tipo, de personas, pero también de mercancías y de capitales. Una ciudad higiénica ${ }^{12}$, que debe estar debidamente saneada para evitar los miasmas y las pestilencias, pero también otros peligros sociales, como los generados por una parte importante de población (pobres, vagabundos, inmigrantes poco exitosos) que terminan por configurar otra ciudad, que se superpone o que se anexa a la urbe ideal, que resulta amenazadora y foránea, y que será objeto de

7. Gorelik, Adrián. Ciudad, modernidad, modernización. Universitas Humanística. 2003; 56: 11-17.

8. Romero, José Luis. Latinoamérica: las ciudades y las ideas. 5a ed. Buenos Aires: Siglo XXI; 2001.

9. Sin duda, una de las más brillantes reflexiones sobre la relación entre utopía e innovación urbana es la realizada por Gustavo Vallejo a propósito de su estudio de la ciudad de La Plata: Vallejo, Gustavo. Escenarios de la cultura científica argentina. Ciudad y universidad (1882-1955). Madrid: CSIC; 2007. En particular el capítulo titulado «La utopía de la ciencia», p. 53 y ss.

10. Padín, Luis. Utopía y distopía en Domingo Faustino Sarmiento. De Argirópolis a conflictos y armonías de las razas en América. Tesis doctoral inédita. Departamento de Humanidades y Artes. Universidad Nacional de Lanús (Argentina).

11. Tomado de Petrone, Mario. Aproximaciones a las ciudades latinoamericanas. EXPLORA América Latina. Canal Encuentro [material docente] Disponible en: http://estatico.buenosaires.gov.ar/ areas/educacion/cepa/ciudades_latinoamericanas.pdf [citada 17 May 2011].

12. Véase Armus, Diego. La ciudad higiénica entre Europa y Latinoamérica. In: Lafuente, Antonio; Elena, Alberto; Ortega, Maria Luisa, eds. Mundialización de la ciencia y la cultura nacional. Madrid: Doce Calles; 1993, p. 587-596. También Armus, Diego. La ciudad impura. Salud, tuberculosis y cultura en Buenos Aires, 1870-1950. Buenos Aires: Edhasa; 2007. 
reformas urbanas de gran envergadura, no exentas de una voluntad científica de regulación y defensa social.

En el presente ensayo pretendemos estudiar el marco ideológico y científico en el que se desarrolló la renovación urbanística llevada a cabo por el que fuera Intendente de Santiago de Chile entre 1872 y 1875, Benjamín Vicuña Mackenna (1831-1886), autor prolífico, intelectual positivista y político liberal-conservador, convertido en el gran reformador de la ciudad de Santiago. Prestaremos especial atención al origen de sus objetivos modernizadores, íntimamente relacionados con el ya aludido programa de instauración de una cultura (civilización) urbana por parte de la elites latinoamericanas ${ }^{13}$, y analizaremos las estrategias de higiene y defensa social que dichas reformas llevaron implícitas.

\section{Del viaje iniciático a la voluntad reformadora}

Opositor político del presidente Manuel Montt, Vicuña Mackenna se vio obligado a abandonar Chile en 1852, aprovechando el destierro para recorrer Estados Unidos y Europa, en un viaje formativo que, a la postre, sería fundamental en la elaboración de sus propuestas reformadoras. Según relata en su diario de viaje, publicado a su regreso a Chile ${ }^{14}$, y más tarde en otras obras $^{15}$, Vicuña Mackenna se muestra fascinado por los avances técnicos y los nuevos medios de información y de comunicación. El teléfono y el telégrafo, cuya eficacia tiene oportunidad de comprobar durante su estancia en Estados Unidos, le llevan a vislumbrar tecno-utopías que simbolizan el más alto grado de modernidad:

13. Sobre el papel del intelectual convertido en funcionario y burócrata en relación con estos procesos de urbanización en América Latina, son clásicos los trabajos de Morse, Richard. Los intelectuales latinoamericanos y la ciudad (1860-1940). In: Ardió, Jorge; Morse, Richard; Schaedel, Richard, comps. Ensayos histórico-sociales sobre la urbanización de América Latina. Buenos Aires: CLACSO-Ed. Siap; 1978, p. 91-112; y de Rama, Ángel. La ciudad letrada. Hanover: Ediciones Norte; 1984.

14. Vicuña Mackenna, Benjamín. Páginas de mi diario durante tres años de viaje, 1853-1854-1855. Santiago: Imprenta del Ferrocarril; 1856.

15. Vicuña Mackenna, Benjamín. Miscelánea. Colección de artículos, discursos, biografías, impresiones de viaje, ensayos, estudios sociales, económicos, etc. Santiago: Imprenta de la Librería del Mercurio; 1872. 
«Y por qué al mismo tiempo no se pediría al telégrafo igual servicio domestico? Conocí yo hace años en Nueva York un hombre eminente que ha dado su nombre (Ogden) a uno de los pueblos de la gran ruta del Atlántico al Pacífico llamado a grandes destinos, i este innovador abrigaba la firme convicción de que en el curso de los tiempos se suprimiría del trato de la caligrafía, los correos, el papel de cartas i hasta las plumas de acero, porque, a su juicio, cada vecino debería tener en su cuarto de trabajo una maquinita alfabética sumamente sencilla i barata, con la cual, puesta en contacto con los alambres de la calle, podía escribir, conversar, hacer negocios, con las cuatro partes del mundo» ${ }^{16}$.

El político liberal veía en los avances tecnológicos una herramienta fundamental en el desarrollo de una sociedad civilizada que, tras modificar la estructura colonial, propiciase una época dinámica en la que los flujos de información desempeñaran un papel fundamental en la expansión del modelo económico capitalista, en cuyo marco ideológico puede explicarse el modelo utópico civilizatorio defendido por Vicuña Mackenna: «La era de la Independencia queda cerrada. La era de la Civilización está, pues, desde hoy abierta» ${ }^{17}$.

Pero es en Europa donde el futuro intendente de Santiago encontrará los referentes teóricos y prácticos más claros para lo que más tarde será su proyecto reformador. Lector infatigable, va adquiriendo conocimientos de historia, ingeniería, urbanismo, geología, sociología, que afianzan su formación positivista. En París visita la universidad, así como el Instituto de Francia y sus cinco «facultades» ${ }^{18}$, pero sobre todo se interesa por el proyecto de modernización urbanística que Napoleón III había encargado al barón Haussmann, al que más tarde nos referiremos y que en buena medida inspirará las futuras reformas santiaguinas.

En Londres, visita el British Museum, donde queda deslumbrado por la expansión de la civilización británica y su conquista de la materialidad de otras culturas:

16. Vicuña Mackenna, n. 14, p. 228. Se respeta la grafía original.

17. Vicuña Mackenna, n. 14, p. 112.

18. Vicuña Mackenna, n. 14, p. 117. Aunque alude a las facultades, se está refiriendo, lógicamente, a las cinco Academias que componían, y siguen componiendo, el Institut de France: Académie française, Académie des inscriptions et belles-lettres, Académie des sciences, Académie des beaux-arts y Académie des sciences morales et politiques. 
«Esa institución es el Museo Británico, verdadero compendio de la historia, de la ciencia i del desarrollo del mundo, que dentro de sus colosales tapias de negrusco granito contiene todo lo que el hombre puede saber. Allí la Gran Bretaña ha acumulado todos los espolios de sus conquistas en el universo, desde los frisos del Partenón a las flechas plumas de los aborígenes de Oceanía; desde los dioses mitolójicos de Nínive i Babilonia hasta las huacas de Trujillo y el Cuzco. Allí está el alfabeto titánico de la creación, desde los esqueletos gigantescos del mastodonte i del megaterio hasta la formación microscópica de la mas humilde luciérnaga de la noche, de las mas imperceptibles de las orugas de las plantas» ${ }^{19}$.

La ciencia como mecanismo de poder político, el conocimiento científico como elemento imprescindible en la administración del Estado y en la construcción de la nación. Una ciencia llamada a conquistar el mundo, a dominarlo y civilizarlo mediante la imposición de los valores, las normas y la cultura europeas. Estas ideas son las que Vicuña Mackenna va aprendiendo en su viaje a la «civilización» y que, en cierto modo, ofrece una imagen especular de otros viajes realizados en sentido contrario por los europeos. Sin olvidar el viaje romántico a tierras exóticas, recuerda sobre todo el viaje del naturalista (botánico, zoólogo o antropólogo) que refería y representaba la naturaleza de lejanas tierras ${ }^{20}$, por más que lo que nuestro viajero explora y «descubre» sean nuevos mundos tecnológicos y no siendo la naturaleza sino la cultura (esto es, la naturaleza trasformada) el objeto de su interés.

El recorrido de Vicuña Mackenna tiene elementos de un viaje enciclopédico, en el sentido de Serrés, de adquisición de conocimientos, de tránsito «por un lugar privilegiado donde es posible experimentar directamente una teoría científica» ${ }^{21}$, o, en el caso que nos ocupa, comprobar los logros de la ciencia en la construcción de la moderna civilización occidental. Y es también un viaje iniciático, pues no en vano el joven político exiliado, a través de la experiencia vital y de los conocimientos adquiridos, toma conciencia de sí mismo, y termina por asumir una misión - civilizatoria y modernizadora- que se traducirá en las reformas urbanas que más tarde comentaremos.

19. Vicuña Mackenna, n. 14, p. 318.

20. Véase Pimentel, Juan. Testigos del mundo. Ciencia, literatura y viajes en la llustración. Madrid: Marcial Pons Historia; 2003.

21. Serres, Michel. Hermes I. La communication. Paris: Éditions Minuit; 1968, p. 211. 
Pero veamos, brevemente, el punto de partida doctrinal de tales reformas. En el fondo se trataba de imponer una civilización, fuertemente eurocéntrica, que exigía la modificación (o desaparición) de la población que no se ajustara a los cánones aceptados, interiorizados e impuestos por la nueva elite liberal latinoamericana ${ }^{22}$. La ciencia positivista, y en particular el evolucionismo ${ }^{23}$ y el degeneracionismo ${ }^{24}$, ofrecieron buena parte del soporte científico con el que acometer la construcción de una modernidad y de una identidad nacional de la que debían excluirse elementos degenerados, detritus sociales que difícilmente podrían contribuir al mencionado objetivo. La relación entre degeneración biológica y decadencia social, tantas veces argumentada ${ }^{25}$, aparece en el pensamiento de Vicuña Mackenna con gran claridad cuando advierte del atraso de la raza chilena, especialmente de los antiguos campesinos o gañanes, vistos como herederos culturales de los indígenas - nomadismo, poligamia, indisciplina laboral-y del pasado agrario y latifundista de la colonia, siempre subordinado al terrateniente o a la iglesia. Por el contrario, el nuevo ciudadano que Vicuña Mackenna vislumbra debe formar parte de la modernidad industrial y urbana, proletariado de fábrica, consumidor de tecnología, cosmopolita por relaciones laborales y por acceso a la información. Civilización - y economía - expansiva, en suma, propia de un liberalismo que se va afianzando paulatinamente.

22. Una interesante reflexión sobre el eurocentrismo en América Latina puede encontrarse en Quijano, Aníbal. Colonialidad del poder, eurocentrismo y América Latina. In: Lander, Edgardo (comp.). La colonialidad del saber: eurocentrismo y ciencias sociales. Buenos Aires: CLACSO; 2000, p. 201-246.

23. Una reciente aproximación a estas dinámicas puede encontrarse en Vallejo, Gustavo; Miranda, Marisa, dirs. Derivas de Darwin. Cultura y política en clave biológica. Buenos Aires: Siglo XXI Editora Iberoamericana; 2010.

24. Existe una amplia bibliografía al respecto, en la que puede apreciarse las variaciones del discurso degeneracionista en función del contexto socio-cultural que se considere. Véanse, entre otros, Urias, Beatriz. Degeneracionismo e higiene mental en el México posrevolucionario (1920-1940). Frenia. 2004; 4 (2): 37-76. Ferla, Luis. Feios, sujos e malvados sob medida. A utopia médica do determinismo. Sao Paulo: Alameda; 2009. Lvovich, Daniel; Boholavsky, Ernesto. Elitismo, violencia y degeneración física en los diagnósticos de las derechas argentina y chilena (18801945). Nuevo Mundo Mundos Nuevos. Debates. 2009. Disponible en http://nuevomundo. revues.org/57777 [citada 9 Jun 2011]. Para España, puede verse Campos, Ricardo; MartínezPérez, José; Huertas, Rafael. Los ilegales de la naturaleza. Medicina y degeneracionismo en la España de la Restauración (1876-1923). Madrid: CSIC; 2000, p. 153 y ss.

25. Véase, por ejemplo, Campos, Ricardo; Huertas, Rafael. Degeneración biológica y decadencia social. Datos para un imaginario patrio. In: Naranjo, Consuelo; Serrano, Carlos, eds. Imágenes e imaginarios nacionales en el ultramar español. Madrid: CSIC-Casa de Velázquez; 1999, p. 47-65. 
En este sentido, el retraso social es argumentado a partir de la pobreza del mundo rural y de la estética indígena (vestimenta, fisiología), que se presenta como la antítesis de la civilización:

«Mirad el traje del campesino, del gañán. El de los pobladores de la ciudad se ha transformado casi por entero; pero la vestimenta del peón es siempre la misma; las mismas ojotas, el mismo calzón asiático de tocuyo, el mismo poncho araucano que tenía hasta $1810 »^{26}$.

En la década de 1870, una gran masa de población campesina emigró a los núcleos urbanos chilenos ${ }^{27}$, lo que introdujo problemas específicos no solo en la configuración de la ciudad sino en las relaciones entre sus habitantes. Los nuevos pobladores, procedentes del campo, eran vistos con desconfianza, porque representaban decadencia y peligrosidad social, pero sobre todo un gran impedimento para el progreso:

«Mirad como todo ha progresado en Chile de una manera asombrosa, incluso la agricultura en su material, en sus semillas, en sus bestias, en todo, menos en el hombre, en el inquilino, en el peón, que es el eje real de todo mecanismo. Asomad si no la cabeza al postigo, en cualquiera de vuestros viajes por rieles a la hacienda i notareis que el rancho que acabáis de pasar es la misma infeliz choza de cincuenta años, de ahora un siglo, de la época de la conquista; la misma basura, el mismo fogón, los propios niños raquíticos i descamisados, i el hambre i el abandono i la miseria i la barbarie en todo» ${ }^{28}$.

Esta visión del hombre bárbaro, mitad indígena, mitad asiático, constituye el símbolo de lo que hay que transformar no solo en una raza, sino en una ciudad. Su miseria - biológica y social- es lo que hay que erradicar de la civilización. Se hace necesario acabar tanto con los miasmas pestilentes que transmiten enfermedades como con los miasmas sociales ${ }^{29}$, que igualmente contaminan, según la conocida metáfora, el gran organismo social.

26. Vicuña Mackenna, n. 14, p. 408.

27. La Transformación de los Barrios Pobres I. Santiago, 28 de Abril de 1872, Editorial del Ferrocarril. Reproducido en Grez Toso, Sergio. La cuestion social en Chile. Ideas y debates precursores (1804-1902). Santiago: Ediciones de la Dirección de Bibliotecas, Archivos y Museos; 1995, p. 211.

28. Vicuña Mackenna, n. 14, p. 408.

29. Corbin, Alain. El perfume o el miasma. El olfato y lo imaginario social. Siglos XVIII y XIX. México: Fondo de Cultura Económica; 1987. 
Para Vicuña Mackenna es objetivo primordial modificar la «raza» chilena, pero es consciente de las limitaciones de una actuación sobre las biologías particulares. Se lamenta del fracaso que, a su juicio, había sufrido el primer intento para «blanquear» ${ }^{30}$ la población con emigrantes germanos hacia 1850:

«Por otra parte, de qué manera se haría, la aglomeración de razas, la transfusión de sangre, único arbitrio que fecundiza las falanges emigratorias? Donde está la alianza posible del huaso i del europeo en las condiciones presentes de aquel i del último? Esta es la cuestión primordial, i esta es la esplicación, llana, sin ambajes de falsos éxitos, que explica el aislamiento absoluto, por no decir la hostilidad latente, de los grupos jermánicos que han mudado de casa de Bremen o Hamburgo a Puerto Montt u Osorno, pero que jamás han emigrado a nuestro país en el sentido social, político i doméstico de esta palabra» ${ }^{31}$.

Si la emigración blanca no había traído los resultados esperados, se hacía necesario regenerar a la población con otras estrategias que abarcaran lo racial, pero también lo cultural. La ciudad «modificada» aparece entonces como un ideal a conseguir, un «organismo» al que se le aplicará la necesaria «transfusión de sangre» renovada. Las metáforas biológicas se suceden porque la alianza entre biología, medicina y sociología monopolizan el discurso político. Una especie de nacionalismo orgánico domina el proyecto de transformación urbana de Santiago de Chile llevado a cabo por Vicuña Mackenna:

«Nuestro caso de actualidad, nuestro progreso verdadero, no es, pues, de importación extraña: es esencialmente una cuestión casera y preparatoria. Podemos primero el árbol envejecido: después practicaremos el injerto. Levantemos a nuestra raza aborigen de su postración secular» ${ }^{32}$.

30. Como se sabe, las políticas inmigratorias de «blanqueamiento» han sido estudiadas de manera particular en contextos geográficos con una importante población de esclavos negros. Para Brasil, el pionero y ya clásico libro de Skidmore, Thomas. Black into white. Race and nationality in Brazilian thought. Oxford: Oxford University Press; 1974. Para las Antillas, citaremos, a modo de ejemplo, un trabajo más reciente de Naranjo, Consuelo. El temor a la africanización: Colonización blanca y nuevas poblaciones en Cuna (el caso de Cienfuegos). In: Piqueras, José A., ed. Las Antillas en la era de las Luces y la Revolución. Madrid: Siglo XXI; 2005, p. 85-122.

31. Vicuña Mackenna, n. 14, p. 416.

32. Vicuña Mackenna, n. 14, p. 416. 
Esta es la utopía que el intendente persigue, considerar la ciudad de Santiago como un gran organismo, como un gran cuerpo en el que la salud equivale a desarrollo social y la enfermedad a todo lo que impida dicho desarrollo, un conjunto de patologías sociales que deberán combatirse y extirparse. «Podar el árbol envejecido para después practicar el injerto», tal como se expresa en la cita anterior, implicaba un proceso en el que, antes de modernizar y de reformar la ciudad, imitando las grandes urbes europeas, era preciso extirpar determinadas formas de vida y de hábitat que se contraponían al modelo de la ciudad moderna y civilizada y que constituían una especie de anti-modelo, de anti-ciudad.

\section{La reforma urbana de Vicuña Mackenna}

No cabe duda que las relaciones espaciales de los cuerpos humanos determinan, en buena medida, la manera en que las personas reaccionan unas con respecto a otras, la forma en que ven y escuchan, en si se tocan o están distantes, etc. Estas necesidades de relación entre individuos o entre grupos jerarquizados socialmente han condicionado planes y diseños urbanísticos; pero además, la concepción científica que se tenía del cuerpo ha influido en la manera de entender el espacio urbano. Por ejemplo, cuando Harvey, a comienzos del siglo XVII, describió la circulación de la sangre, ofreció una nueva imagen del cuerpo no solo para la ciencia médica, sino también para la ciencia política y para el urbanismo. Adam Smith supuso en La riqueza de las naciones que el libre mercado de trabajo y de bienes operaba de una manera similar a la circulación de la sangre en el cuerpo humano. La circulación e intercambio de mercancías y dinero parecía mucho más provechosa que la posesión fija y estable de la propiedad. Frente a la sociedad feudal, el incipiente capitalismo se movía, libre de viejas ataduras, a lugares o a gentes concretas. En definitiva, como ha indicado Gustavo Vallejo, «la figura de la circulación condensa la construcción analógica de la ciudad industrial como traducción física de las necesidades y los ideales del capitalismo» ${ }^{33}$. Es evidente que las descripciones anatómicas y fisiológicas de la medicina moderna influyeron también en las concepciones urbanísticas de los planificadores ilustrados: desde Harvey, la cuidad tendrá pulso, respiración y

33. Vallejo, n. 9, p. 71. 
grandes arterias y venas por las que circularán las personas; desde Willis, las urbes contarán también con fibras y energía nerviosa ${ }^{34}$.

Los paralelismos entre cuerpo individual y cuerpo social son muy evidentes en el pensamiento sociológico de la época y Vicuña Mackenna no hace sino incorporarlos y aplicarlos a su ya citado proyecto de transformación de la ciudad de Santiago. Durante los años en que ocupó el cargo de intendente de la capital chilena (1872-1875) llevó a cabo una serie de reformas urbanas entre las que destacan por su importancia y por su simbolismo, de un lado, la modificación del cerro Huelén (en lengua mapuche), rebautizado como cerro de Santa Lucía por los conquistadores españoles, que representa y define la ciudad burguesa, moderna y europea y, de otro, la construcción del Camino de Cintura o Muro Sanitario, que aislará el suburbio, esa anti-ciudad que es preciso regenerar en aras de la misma modernidad. El propio Vicuña Mackenna diferencia claramente los dos sectores urbanos que pretende segregar:

«Define la ciudad estableciendo los límites propios de ésta, demarcación que hoy día forma una de sus más imperiosas necesidades, con relación a la edilidad (es decir, al pavimento, las aceras, las plantaciones, el alumbrado, la seguridad, el uso del agua potable, etc.), creando la ciudad propia, sujeta a los cargos i beneficios del municipio, i los suburbios, para los cuales debe existir un régimen aparte, menos oneroso y menos activo» ${ }^{35}$.

\subsection{La ciudad propia: la Montaña Mágica de Santa Lucía ${ }^{36}$}

La remodelación del cerro de Santa Lucía, situado en el centro de la ciudad, constituye, sin duda, una de las grandes novedades urbanísticas que Vicuña Mackenna introduce durante su mandato. Un cerro seco y polvoriento que es transformado en un vergel en el que se instalan fuentes, paseos, jardines, miradores, etc. En definitiva, un diseño de parque urbano que, desde el punto de vista simbólico, supone la conquista geográfica de las cotas

34. Sennet, Richard. Carne y piedra: el cuerpo y la ciudad en la civilización occidental. Madrid: Alianza editorial; 1997.

35. Vicuña Mackenna, Benjamín. La transformación de Santiago. Notas e indicaciones. Santiago: Imprenta de la librería del Mercurio; 1872, p. 18.

36. Tomamos el término «montaña mágica» de la obra de Pérez de Arce, Rodrigo. La montaña mágica: el cerro Santa Lucía y la ciudad de Santiago. Santiago, Chile: Ediciones ARQ; 1993. 
montañosas de la ciudad, pero también el triunfo de la higiene (Figura 1). La obra del cerro Santa Lucía vino a transformar el vertedero de basuras que había sido este lugar por mucho tiempo, convirtiéndolo en un área verde que trajera aire limpio y eliminara las pestilencias de la ciudad, un verdadero nuevo pulmón para este cuerpo urbano:

«Por el mismo principio, es ahora cuna de asombro que el Santa Lucia esta gran casa de sanidad hay y ha sido tantos años convertido en verdadero foco de infección y de miasmas pestilentes, en el corazón mismo de la ciudad» ${ }^{37}$.

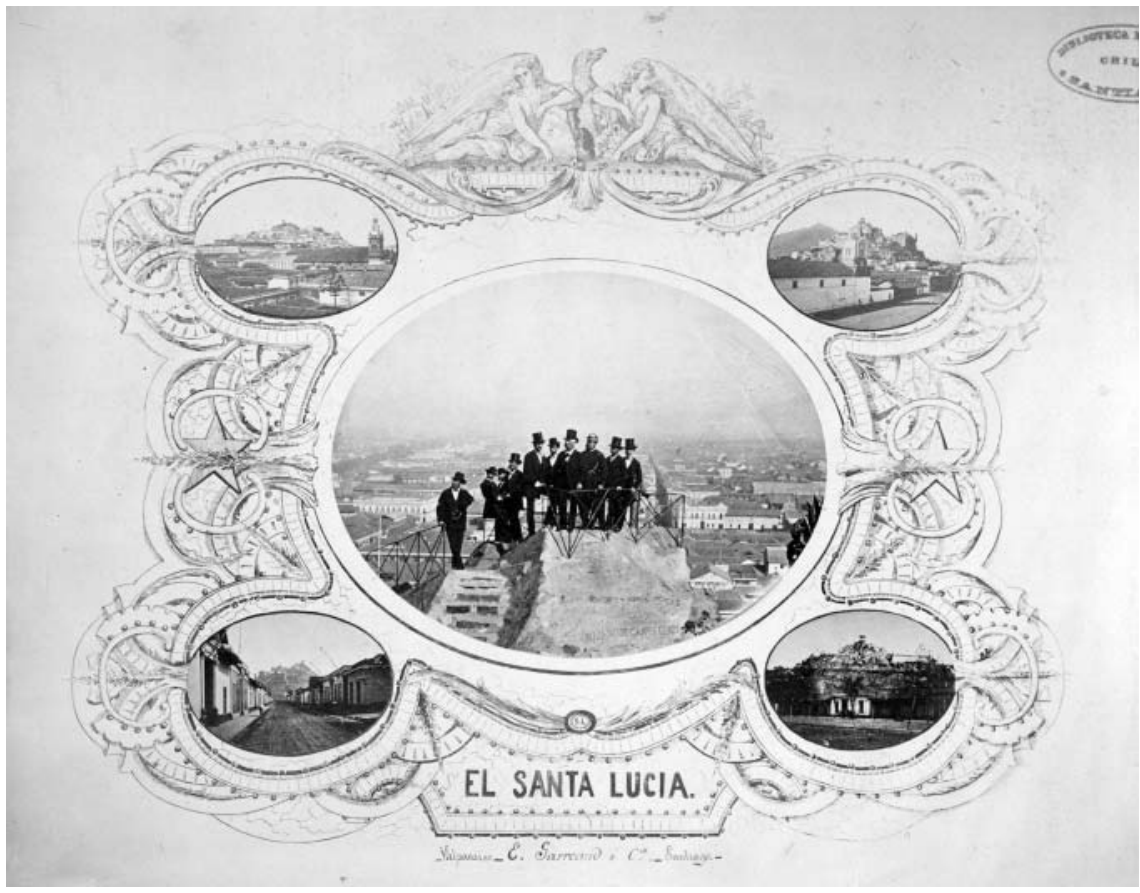

Figura 1. El intendente B. Vicuña Mackenna y su equipo asesor urbanista en la cima del cerro Santa Lucía. Fuente: Vicuña Mackenna, Benjamín. Álbum de Santa Lucia. 1874. Archivo Fotográfico, Biblioteca Nacional, Santiago de Chile.

37. Vicuña Mackenna, Benjamín. Álbum de Santa Lucia: colección de las principales vistas, monumentos, jardines, estatuas i obras de arte de este paseo. Dedicado a la municipalidad de Santiago por su actual presidente B. Vicuña Mackenna. Santiago de Chile: Imprenta de la Librería Mercurio; 1874, p. 4. 
Los paseos circulares que rodean el cerro de Santa Lucía y sus zonas adyacentes suponen también un primer límite urbano, una circunvalación que marca la separación entre zonas urbanas incompatibles. Para la zona protegida, la que habitan las elites, se propone: «Crear en derredor de la ciudad una serie de paseos circulares en embellecerse en breve tiempo con hermosas quintas i casa de recreo, que contribuirán a hacer mas sano el clima de la localidad» ${ }^{38}$.

Pero si la función sanitaria o higiénica del cerro resulta evidente en este proyecto «orgánico» de Vicuña Mackenna, no lo es menos su misión de proporcionar materia prima, piedra basáltica fundamentalmente, para la urbanización de las calles; en este sentido, el cerro de Santa Lucía estaba llamado también a convertirse en una especie de corazón-motor, donde la modernidad de la ciudad, inauguraría un artefacto de minería industrial urbana. Así, en el proyecto urbanístico se aunaba ciencia y tecnología, grandes obsesiones del intendente y, por supuesto, el lucro como resultado final de esta intervención, porque la explotación del cerro: «reportará por años, tal vez siglos, una renta no despreciable» ${ }^{39}$.

Tampoco puede olvidarse que, junto a las razones higiénicas, y a las industriales, se va desarrollando toda una estructura comercial y de ocio que representa otra faceta de modernidad urbana, la que articula un nuevo escenario económico y de consumo y un reajuste de los usos mercantiles y residenciales, y que acaba constituyéndose en lo que algunos autores han llamado «mito urbano»; esto es, «un elemento de referencia colectiva que, desde el seno de los sistemas discursivos desarrollados por los poderes públicos (o privados), establece una causalidad directa entre morfologías espaciales y las prácticas de los agentes sociales ${ }^{40}$.

La construcción de pasajes techados y elegantes comercios, como la Galería de San Marcos, permiten instalarse a determinados comerciantes suficientemente distanciados de los mercadillos al aire libre, del comercio popular y de la cultura de un homo ludens ${ }^{41}$ que frecuenta espacios de diversión transgresores o peligrosos (tabernas, prostíbulos, casas de juego). Bajo el acero y el vidrio queda establecido el gran comercio, claramente

\footnotetext{
38. Vicuña Mackenna, n. 35, p. 19.

39. Pérez de Arce, n. 36, p. 151.

40. Dagnaud, Monique. Le mythe de la qualité de la vie et la politique urbaine en France. Paris: Mouton; 1978.

41. Huizinga, Johan. Homo ludens. Madrid: Alianza Editorial/Emecé Editores; 2002.
} 
diferenciado de la venta ambulante y de los mundos sociales vinculados a la mala vida ${ }^{42}$. Los escaparates empezaron a mostrar otra ciudad, con productos de consumo en una nueva urbe llena de oportunidades, con el sueño de la industrialización, y con la vana promesa de riqueza, bienestar y avances tecnológicos.

La montaña mágica de Vicuña Mackenna terminaba con una serie de castillos burgueses, llenos de jardines greco-latinos con esculturas de divinidades, símbolos de occidente, hechos en acero y hierro fundido, elementos de la industrialización del siglo XIX (Figura 2). Finalmente, se pretendía instalar en la montaña un monumental reloj, un faro y un ferrocarril. Pro-

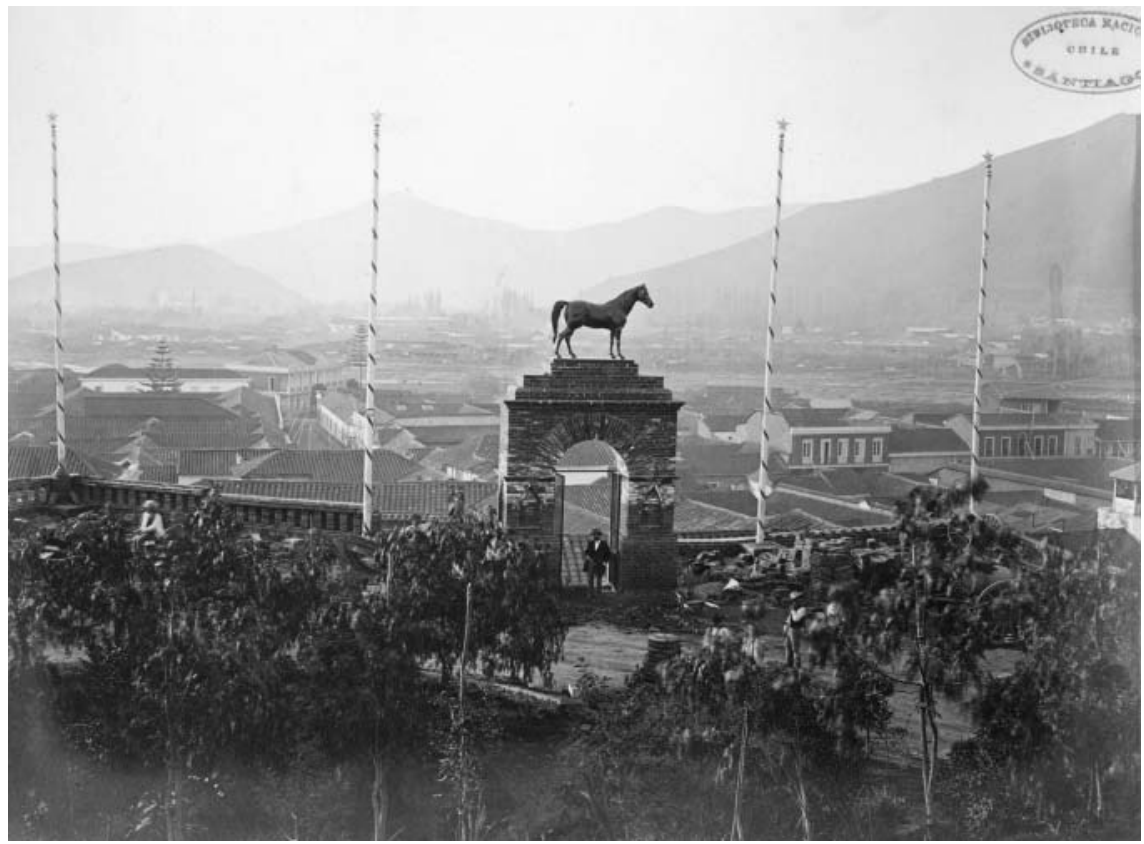

Figura 2. La portada del caballo. Fuente: Vicuña Mackenna, Benjamín. Álbum de Santa Lucia. 1874. Archivo Fotográfico, Biblioteca Nacional, Santiago de Chile.

42. Sobre la importancia y las dificultades para definir el concepto de la «mala vida», véase Campos, Ricardo. La clasificación de lo difuso: el concepto de mala vida en la literatura criminológica del cambio de siglo. Journal of Spanish Cultural Studies. 2009; 10 (4): 399-422. También Cleminson, Richard; Fuentes, Teresa. La mala vida: source and focus of degeneration, degeneracy and decline. Journal of Spanish Cultural Studies. 2009; 10 (4): 385-397. 
yectos que no llegaron a concretarse pero que poseen una enorme fuerza simbólica; así, la luz de la razón - con su connotación ilustrada - terminaría con el peso de la noche ${ }^{43}$, el reloj, como el elemento de control de la cotidianidad de los ciudadanos, representa la imposición de reglas calculables para disciplinar las relaciones sociales ${ }^{44}$, a la vez que introduce la metáfora de la ciudad-máquina (nueva utopía tecnológica), perfectamente sincronizada en su funcionamiento ${ }^{45}$. En cuanto al ferrocarril, éste fue instalado en Valparaíso (los ascensores urbanos de la ciudad-puerto) en aquellos mismos años, adelantándose al proyecto del intendente.

No cabe duda que toda esta remodelación está directamente inspirada en la gran reforma de París llevada a cabo por el barón Haussmann entre 1853 y 1870, y a cuyo proyecto, como ya hemos apuntado, tuvo acceso Vicuña Mackenna durante su viaje a la capital francesa. Tras la demolición de las estrechas e insalubres calles medievales de París, la construcción de anchos boulevards, grandes plazas y amplios jardines garantizaban espacios abiertos y salubres, evitando el hacinamiento de la población y favoreciendo el comercio y el flujo de personas. Reformas de gran envergadura que permitieron la expropiación forzosa de los viejos inmuebles derruidos y el desplazamiento de los obreros y las clases populares a la periferia de la ciudad, sin olvidar que la anchura de las calles permitía el rápido desplazamiento del ejército o de la policía y dificultaba la construcción de barricadas, con lo que las reformas urbanas cumplieron también el objetivo militar de reprimir las revueltas sociales o los conatos revolucionarios ${ }^{46}$.

Vicuña Mackenna puede ser considerado el «Haussmann chileno» ${ }^{47}$. Su proyecto responde en el fondo a las mismas preocupaciones: transformar

43. Expresión con la que Diego Portales, ministro de la República de Chile en 1830, se refirió a la tradición colonial como factor de estancamiento del progreso social en el Estado chileno. Jocelyn-Holt, Alfredo. El peso de la noche: nuestra frágil fortaleza histórica. Buenos Aires: Ariel; 1997.

44. Spitzer, Steven. The rationalization of crime control in capitalist society. Contemporary Crises. 1979; 3 (2): 187-206.

45. Ferla, Luis. A cidade-máquina em São Paulo, Sinfonia da Metrópole. Cadernos de Antropologia e Imagem. 2006; 23: 81-96.

46. Existe una amplia bibliografía al respecto; a modo de ejemplo: Moncan, Patrice; Heurteux, Claude. Le Paris d'Haussmann. Paris: Ed. du Mécène; 2002. También Carmona, Michel. Haussmann. Paris: Fayard; 2000. Cars, Jean des. Haussmann: la gloire du Second Empire. Paris: Perrin; 2000.

47. Leyton, César. Historia de la ortopedia urbana. Caber Humanitatis. 2005; 35. Disponible en http://www.lapetus.uchile.cl/lapetus/archivos/1255975381Historiadelaortopediaurbana187 0(CésarLeyton).pdf [citada 27 May 2011]. 
Santiago en una ciudad higiénica y moderna, conjurando el temor a las turbas de obreros o campesinos, a esas clases peligrosas procedentes de los suburbios, que debían mantenerse suficientemente alejadas del núcleo limpio y ordenado de la ciudad burguesa ${ }^{48}$.

Como ya hemos indicado, el apelativo de «montaña mágica» aplicado al cerro de Santa Lucía fue utilizado por primera vez por el prestigioso arquitecto chileno Rodrigo Pérez de Arce $^{49}$. Sin terminar de quedar muy claro hasta qué punto su intención es aludir a La montaña mágica (1924) de Thoman Mann, la analogía nos resulta oportuna por al menos dos motivos. Por un lado, podrían establecerse ciertas similitudes, más simbólicas que reales, entre el nuevo cerro de Santa Lucía y la montaña de Davos, en los Alpes suizos, donde se sitúa el sanatorio antituberculoso escenario de las peripecias vitales de Hans Castorp: la belleza del panorama que puede observarse desde sus cimas, pero sobre todo, la pureza del aire y las posibilidades de una suerte de climatoterapia, sugerida en el proyecto de Vicuña Mackenna, y sin duda muy evidente en la obra de Mann ${ }^{50}$. Pero, por otro lado, como es bien sabido, La montaña mágica es también la alegoría de una Europa en crisis y una metáfora de la decadencia burguesa. Una burguesía que habita en un mundo herméticamente cerrado, en el que su protagonista vive una realidad fingida hasta que los cañonazos de la Gran Guerra le sacan violentamente de su ensoñación. No podemos dejar de apuntar que, salvando las distancias, el cerro de Santa Lucía tiene también ese elemento de mundo cerrado y de realidad fingida, frente a la realidad que le circunda y que le amenaza (Figura 3).

\subsection{El aduar africano frente a la ciudad europea}

El suburbio, el arrabal, esas zonas por las que las ciudades han crecido siempre de modo descontrolado y antihigiénico, donde viven las clases más desfavorecidas, y situadas, en general, extramuros o en la periferia,

48. Se trata, como ya hemos indicado, de una dinámica que se repite en toda América Latina. Años más tarde, ya en los albores del siglo XX, Francisco Pereira Passos, alcalde de Rio de Janeiro acometió la gran reforma de dicha ciudad con premisas muy similares, lo que le ha valido el apelativo del «Haussmann tropical». Véase Benchimol, Jaime Larry. Pereira Passos: um Haussmann tropical. Río de Janeiro: SMCTT; 1990.

49. Pérez de Arce, n. 36.

50. Montiel, Luis. La cura climática en La Montaña Mágica de Thomas Mann. Balnea. 2006; 1: 63-78. 


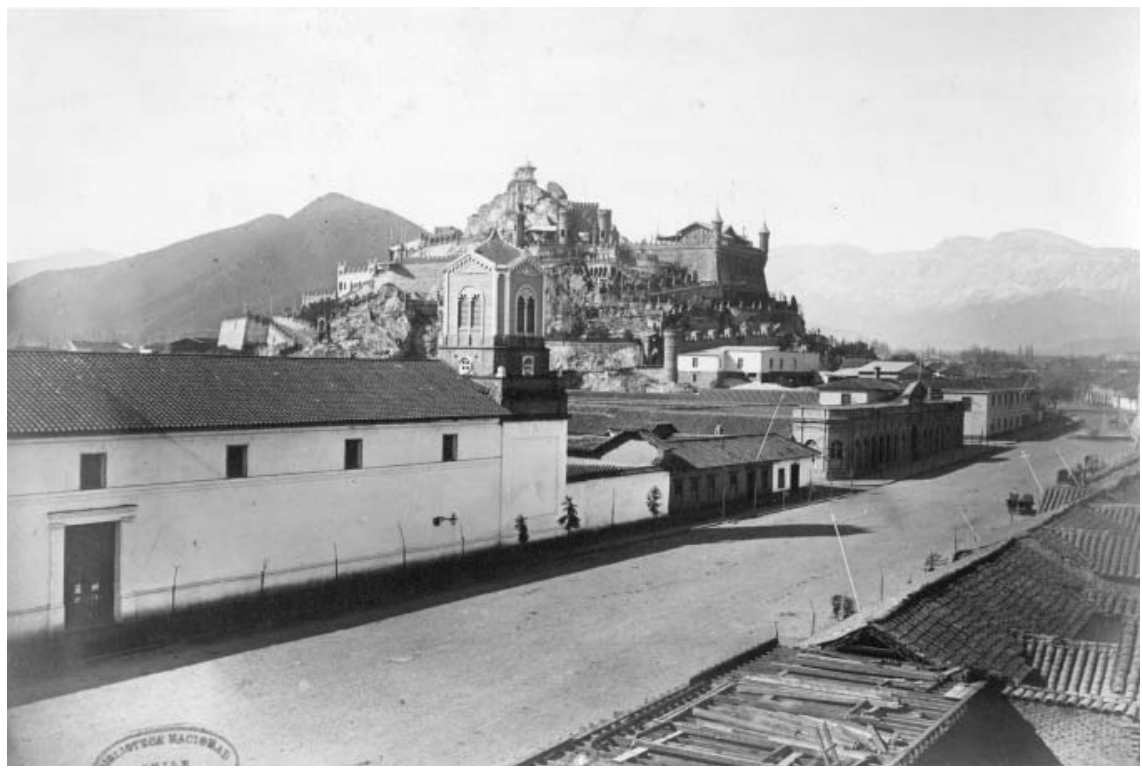

Figura 3. Vista general del Santa Lucía. Fuente: Vicuña Mackenna, Benjamín. Álbum de Santa Lucia. 1874. Archivo Fotográfico, Biblioteca Nacional, Santiago de Chile.

identificadas ya en la historiografía más clásica ${ }^{51}$, cobraron un singular protagonismo en la segunda mitad del siglo XIX y primeras décadas del XX porque simbolizaban, como ya hemos indicado, la antítesis de la ciudad moderna pretendida por los Estados liberales. Probablemente relacionado con el colonialismo español y francés en el norte de África, determinados tipos de suburbios fueron identificados con el aduar africano, es decir, con las pequeñas poblaciones formadas por cabañas y chozas, situadas en las pedanías urbanas de Marruecos y del resto del Magreb. El término pronto se aplicó a los barrios pobres de las ciudades, asociándolo siempre con la cuestión social y con las condiciones antihigiénicas. Así, por ejemplo, la epidemia de cólera que asoló la ciudad española de Salamanca en los años ochenta del siglo XIX, puso en evidencia la existencia de dos ciudades en una:

51. Pirenne, Henry. Les villes du Moyen Age. Essai d'histoire économique et sociale. Bruxelles: Lanmertin; 1927. 
«No obstante merecer Salamanca el sobrenombre de Roma la Chica, por el valor artístico de sus monumentales edificios públicos, las antihigiénicas cualidades de algunos de éstos y casi todos los de índole privada aseméjanse más a un aduar africano que a una ciudad europea» ${ }^{52}$.

De igual modo, el novelista Pío Baroja muestra, en La Busca (1904), un Madrid contradictorio y paradójico, marcado por la llegada de emigrantes: «La Corte es ciudad de contrastes; presenta luz fuerte al lado de la sombra oscura; vida refinada, casi europea, en el centro; vida africana, de aduar, en los suburbios» ${ }^{53}$.

Pues bien, esta misma idea había sido utilizada por Vicuña Mackenna, cuando en su proyecto de transformación urbanística de Santiago, insiste en la existencia de una ciudad blanca, luminosa y limpia y otra mestiza (indígena, africana), oscura y sucia:

«Conocido es el orijen de esa ciudad completamente bárbara, injertada en la culta capital de Chile i que tiene casi la misma área de lo que puede decirse forma el Santiago propio, la ciudad ilustrada, opulenta, cristiana (...) se ha edificado en toda su área un inmenso aduar africano» ${ }^{54}$.

Ya no se trata solo de regenerar a campesinos degenerados, sino de defenderse de la peligrosidad social que encarna una nueva «raza interna», salvaje y bárbara, que es comparada con la población africana y que por su marginalidad, su pobreza, sus enfermedades o su potencial criminalidad suponen una gran amenaza para la civilización que las elites pretenden construir. Población proletaria en formación, situada en los primeros enclaves de la industrialización y considerada inferior desde el punto de vista intelectual, moral y racial:

«peores son esas pocilgas inmundas que agrupadas en los suburbios de nuestra población, i mui principalmente en los que me ocupo, que mas que destinados a dar albergue a civilizados seres humanos, parecen chozas o tolderías

52. López Alonso, Jesús. Estudio histórico-clínico de la epidemia de cólera morbo asiático ocurrida en Salamanca en 1885-1886, precedido de unos apuntes de la climatología de la ciudad. Salamanca: Imprenta Calatrava; 1895, p. 33.

53. La edición utilizada ha sido Baroja, Pío. La lucha por la vida I. la Busca. Edición conmemorativa del centenario del nacimiento de Pío Baroja. Prólogo de Julio Caro Baroja. Madrid: Caro Regio Editor; 1972, p. 53.

54. Vicuña Mackenna, n. 35, p. 24. 
de salvajes, cuya incapacidad intelectual y moral les impidiera mejorar su propia condición» 55 .

Vicuña Mackenna asume con todas sus consecuencias el racismo vigente en América durante la segunda mitad del siglo XIX y que no es, ni mucho menos, una continuidad del racismo de la época colonial. Europa también exportó a las jóvenes repúblicas americanas un racismo científico que tuvo como primer e indiscutible referente a Gobineau y su monumental Essai sur l'inégalité des races humaines, cuyos cuatro tomos fueron publicados en París entre 1853 y 1855, momento en el que, como ya sabemos, Vicuña Mackenna estuvo en Europa. Como es sabido, Gobineau condenaba la mezcla de etnias por considerar que daba como resultado individuos inferiores a los de las razas puras, lo que llevó a algunos a criticar el modelo colonial español y ensalzar el británico, más limpio y segregado, admitiendo en todo momento la superioridad del blanco europeo - y sajón- frente a razas intrínsecamente serviles como la africana, o salvajes, como la indígena americana $^{56}$.

El aduar africano, que Vicuña Mackenna identifica, como veremos a continuación, con la Chimba o suburbio santiaguino, justifica una reforma interior de la ciudad basada en la segregación urbana, un intento de aislar las poblaciones molestas o peligrosas.

\subsection{El muro sanitario y la colonización interna}

La segregación de las clases populares, del aduar africano, requirió una gran obra de circunvalación, de 11 kilómetros de diámetro. Los límites marcados por la muralla medieval o colonial son aquí sustituidos por un gran espacio abierto, un boulevard amplio, que segmenta la ciudad en dos grandes áreas de población, la elite y su ciudad propia y la marginalidad con su arrabal. Al sur, donde se ubican los grandes barrios obreros que están naciendo (matadero) y donde también se sitúan las ranchas de los emigrantes rurales que, como hemos visto, tanto menosprecia el intendente y que la prensa liberal de la época también ataca:

\footnotetext{
55. Vicuña Mackenna, n. 35, p. 26.

56. Sobre estos discursos véase, por ejemplo, Sepúlveda, Isidro. El sueño de la Madre Patria. Hispanoamericanismo y nacionalismo. Madrid: Marcial Pons; 2005, p. 266 y ss.
} 
«Tal atmósfera sólo es a propósito para formar bestias, enfermos, valetudinarios, criminales, aplasta almas y cuerpos. Hasta ahora, el malestar de nuestras clases pobres no nos ha traído sino prostitución, inseguridad, epidemias, una considerable recluta para los presidios y alguna ocupación para el verdugo» ${ }^{57}$.

El «camino de cintura» liberará de este infierno social y delimitará con una nueva frontera urbana, las redes sociales que perduraban desde la colonia. Encerrar en un cordón sanitario la sociabilidad urbana en sus distintas modalidades, una idea aséptica de urbanidad, donde el nuevo ciudadano de Benjamín Vicuña Mackenna participe del ágora pero desde su propio espacio focalizado, circulando perpetuamente, sin mezclarse, sin unirse, sin reproducirse, por seguridad y sanidad, por miedo a la barbarie y a la enfermedad.

Dos ciudades cuyos flujos de negocios y cultura circulen permanentemente, pero que nunca se fusionen en relaciones reproductivas o de clases. El camino de cintura partía en el Campo de Marte (el lugar más aséptico de los cuerpos de la ciudad, el espacio del ejército) rodeando la ciudad por la actual Avenida Matta y llegando en una gran circunferencia a la entrada del barrio norte, a una vía o espacio, la $C_{i m b a^{58}}$, que no había sido controlado nunca y donde el alboroto, la juerga, la chingana (prostíbulo, juego, la resistencia política y la taberna) reinaban en la sociabilidad del campesino, el burgués y el obrero, algo que quiere evitarse a toda costa. Se pretende así una ciudad que prometa tener sitio para todos pero cada uno dentro de un espacio bien compartimentado, ordenado, aislado. Una ciudad que no repita los errores de la colonia y de la hacienda, donde el roto, la china o el gañán se mezclaban con las clases altas, contaminando con su presencia el espacio público:

«Chingana tiene celebrado consorcio con el rancho (que también es un legado jentilicio) y la prole de ambos es el roto, es decir, el hijo del vicio i de la miseria, de la chicha i de la quincha, i así, mientras el roto viva arrebozado en su rito cubierto con su poncho, como el lépero de México, el llanero de

57. Grez Toso, n. 27, p. 212.

58. Chimba en lengua quechua significa al otro lado del río. Véase Rosales, Justo. La chimba antigua. La Cañadilla de Santiago. 1541-1887. Talca: Ediciones Gutemberg; 1994. Es históricamente donde se ha ubicado el bajo pueblo en toda capital o ciudad sudamericana con influencia india. 
Venezuela i el gaucho de las Pampas, es evidente que no existirá el ciudadano, esto es, que no existirá la república sino como nombre: i como realidad existirán los presidios, las penitenciarias i los lazaretos» ${ }^{59}$.

Por eso es preciso, en el sentir de Vicuña Mackenna, proteger la ciudad propia de las múltiples amenazas que la acechan, mediante el aislamiento físico: «[Estableciendo] alrededor de los centros poblados una especie de cordón sanitario, por medio de las plantaciones, contra las influencias pestilenciales de los arrabales» ${ }^{60}$; pero también mediante la regeneración -y recuperación - de los individuos. Su objetivo final es crear una ciudad que conjure dicha amenaza, que haga desaparecer el aduar africano, que garantice la seguridad de las elites burguesas; pero que en su segregación y jerarquización no genere enfrentamiento social. Las medidas higiénicas y moralizadoras dirigidas a las clases populares ${ }^{61}$, responden a la necesidad de asegurar una mano de obra sana y numerosa, evitando la aduana de hombres, generada por la emigración masiva de chilenos hacia Perú en $1870^{62}$.

Pobres, inmigrantes, indígenas, etc., son movilizados y alejados del lugar de residencia de las elites, a la vez que se vigila la expansión de las enfermedades sociales, como la tuberculosis, la sífilis, el alcoholismo, pero también la criminalidad o la prostitución. Todo un programa de defensa y profilaxis social, que evidentemente está teniendo lugar en otros muchos lugares $^{63}$, y cuyo denominador común, independientemente de las especificidades de cada contexto, viene a ser el empeño de combatir la degeneración de la raza, o dicho de otro modo, de conseguir, gracias al concurso inestimable de la eugenesia, la educación y la higiene, en su más

59. Vicuña Mackenna, n. 35, p. 89.

60. Vicuña Mackenna, n. 35, p. 18

61. Sobre las relaciones entre higiene y moral, puede verse Campos, Ricardo. La sociedad enferma. Higiene y moral en España en la segunda mitad del siglo XIX y principios del XX. Hispania. 1995; 55: 1093-1112.

62. El término se utilizó en la época para aludir a la emigración de chilenos hacia el Perú, debido a una crisis social y política que vivía Chile justo en la época de las transformaciones urbanísticas que estamos comentando. Véase La Aduana de Hombres. Santiago 10 de febrero de 1872, Editorial de El Ferrocarril. Recopilado por Grez Toso, n. 27, p. 163-167.

63. La bibliografía disponible es, obviamente, muy extensa, citaremos dos obras colectivas que ofrecen una panorámica de interés con posibilidades comparativas entre varios países de América Latina: Miranda, Marisa; Vallejo, Gustavo, comps. Darwinismo social y eugenesia en el mundo latino. Buenos Aires: Siglo XXI Editora iberoamericana; 2005. También Miranda, Marisa; Girón, Álvaro, coords. Cuerpo, biopolítica y control social. América Latina y Europa en los siglos XIX y XX. Buenos Aires: Siglo XXI Editora iberoamericana; 2009. 
amplio sentido, individuos sanos y fuertes que contribuyan al desarrollo socio-económico y a la construcción de la nación. Una mano de obra sana, gradualmente blanqueada, y suficientemente adaptada a su condición subalterna, que resultaba imprescindible para la instauración definitiva del moderno capitalismo y, en suma, el tantas veces aludido espíritu civilizador.

La Chimba, ese espacio a conquistar, y a colonizar, por el que habían llegado los incas, los españoles o el ejército libertador, es ahora objetivo de la higiene y de la ciencia. Junto a las reformas urbanas y las acciones concretas de control sanitario y social, como la prohibición de la mendicidad, en $1872^{64}$, o la reglamentación de la prostitución, en $1875^{65}$. La modificación del mercado de origen indio, ubicado en la cabecera del río Mapocho en la frontera de la Chimba, también formó parte del proyecto de transformación de la capital durante la administración de Vicuña Mackenna. Asimismo, en 1875 tuvo lugar la primera reforma a la beneficencia pública que permitió la llegada de una elite médica que puede considerarse fundadora de la medicina social en Chile dando lugar, años más tarde, a la creación del Consejo Superior de Higiene, en 1889, en el marco del intenso proceso de industrialización del país durante el mandato del presidente liberal José Manuel Balmaceda (1886-1891) ${ }^{66}$.

Vicuña Mackenna sentó las bases de lo que fue un impresionante entramado institucional que se instaló en la Chimba e intervino científicamente sobre el cuerpo social. A partir del proyecto de Vicuña en 1872, y hasta 1925, fueron apareciendo y modernizándose una serie de instituciones, establecimientos y espacios higienistas que adquirieron una enorme importancia social y se convirtieron en rectoras y reformadoras de una población que producía y se reproducía en el marco de un incipiente modelo industrial. Así, el Cementerio General, la Casa de Orates, la Escuela de Medicina, los hospitales o lazaretos para tuberculosos y apestosos San José y Vicente de Paúl; la Escuela de Odontología; el Instituto de Higiene Pública y Bacterio-

\footnotetext{
64. A propósito del decreto de prohibición de la mendicidad, Santiago, 3 de mayo de 1872. Editorial de El Ferrocarril. Recopilado en Grez Toso, n. 27, p. 219-223.

65. Dicha reglamentación, elaborada en Valparaíso, está dedicada al Intendente B. Vicuña Mackenna como promotor de estas reformas sociales y urbanas. Allende, Ramón. De la reglamentación de la prostitución. Valparaíso: Imprenta Colón; 1875.

66. Entre esta elite médica destacan José Joaquín Aguirre, Adolfo Murillo, Ramón Allende Padín y Adolfo Valderrama. Véase Cruz-Cocke, Ricardo. Historia de la medicina chilena. Santiago: Editorial Andrés Bello; 1995, p. 411.
} 
logía y el Instituto de Medicina Legal ${ }^{67}$. La Chimba es vencida y la ciudad higiénica de Vicuña Mackenna triunfa por todo el siglo XX.

A modo de reflexión final, y como conclusión adicional, cabe decir que el colonialismo europeo en África durante la segunda mitad del siglo XIX y hasta bien entrado el siglo XX, propició la construcción de una jerarquización racial que se aplicó, como hemos visto, al imaginario social y urbano. Determinados discursos y prácticas propias del racismo «científico» fueron utilizados por la elites latinoamericanas, que los aplicaron a sus propias poblaciones marginales, a las que sometieron y colonizaron, viniendo a confirmar, tal como han apuntado otros autores ${ }^{68}$, y el caso del proyecto de Vicuña Mackenna nos parece suficientemente significativo, que colonialismo y modernidad no deben ser entendidos como fases sucesivas en el tiempo (la modernidad como superación del colonialismo), sino como fenómenos coexistentes y fuertemente interrelacionados.

67. Sobre todo este entramado institucional véase, Lautaro Ferrer, Pedro. Higiene y asistencia pública en Chile. Santiago: Imprenta Barcelona; 1911. También Cruz-Cocke, n. 66.

68. Chukwudi Eze, Emmanuel; Paget, Henry; Castro-Gómez, Santiago. El color de la razón: racismo epistemológico y razón imperial. Buenos Aires: Ediciones del Signo; 2008. 


\section{Urban reform and social hygiene in Santiago de Chile. The liberal techno-utopianism of Benjamín Vicuña Mackenna (1872-1875)}

César Leyton Robinson and Rafael Huertas .......................

1.- Introduction. 2.-Fom the journey of initiation to the reforming will. 3.-The urban reform of Vicuña Mackenna. 3.1.-The city itself: the Magic Mountain of Santa Lucía. 3.2.-The African township versus the European city. 3.3.-The health wall and internal colonization.

ABSTRACT: This paper analyzes the main features of the urban reforms by Benjamin Vicuña Mackenna in Santiago de Chile between 1872 and 1875 . We pay special attention to the origin of the objectives of modernization, closely related to the political agenda of Latin American elites to create an urban culture (civilization). We also analyze the strategies of social defence that these reforms implied. The influence of French positivism and the Haussmann project in Paris was very important in the Vicuña Mackenna project and its model of a segregated city: the «European city» itself, —bourgeois, civilized and hygienic — which should be protected, and the "African township», -lower-class feral and unhygienic-, whose population must be regenerated and colonized. 